\title{
Rhythm Not Otherwise Specified ECG Assessment
}

National Cancer Institute

\section{Source}

National Cancer Institute. Rhythm Not Otherwise Specified ECG Assessment. NCI

Thesaurus. Code C111307.

An electrocardiographic assessment of a cardiac rhythm that is not specified in a particular list. 